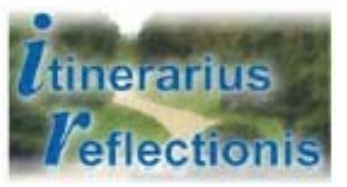

Revista de Educação do Curso de Pedagogia do Campus Avançado de Jataí da Universidade Federal de Goiás

[Vol I-n.3] [Jan/Jul] [2007]

ISSN : 1807-9342

\title{
CONTRIBUIÇÕES DO CURSODE PEDAGOGIA NA FORMAÇÃO DOS PROFESSORES DE EDUCAÇÃO INFANTIL
}

\author{
LIMA, Laís Leni Oliveira ${ }^{1}$ Docente do Curso de Pedagogia CAJ-UFG
}

\section{RESUMO}

Este artigo propõe refletir as contribuições do curso de Pedagogia na formação do profissional para atuar na Educação Infantil (EI). Partimos do entendimento que uma Pedagogia da EI caracteriza-se por sua especificidade no âmbito da Pedagogia, uma vez que esta está ligada com a prática educativa num sentido mais amplo. Entretanto, em sua trajetória, não tem contemplado uma especificidade para a educação de crianças menores de seis $\operatorname{anos}^{2}$. Entendemos que se faz necessário garantir uma política de formação de toda uma universidade pública, gratuita e de qualidade, que forme pedagogos para a EI, que vai de contramão com essas políticas neoliberais, tão em moda na sociedade contemporânea. A produção científica da EI certamente estará contribuindo para uma Pedagogia da infância pertinente aos seus futuros educadores.

Palavras-chave: Formação de Professores, Educação Infantil, Pedagogia da Infância, Estágio

\footnotetext{
ABSTRAT

This article proposes to reflect upon the contributions of a Graduate Course in Early Years Education towards the formation of professionals who will work in this area. We assume that such a Graduate Course is characterized by its specific subjects within the course, as it

${ }^{1}$ Prof $^{a}$. no Dept ${ }^{o}$ de Pedagogia nas Disciplinas de Estágio em Educação Infantil e anos iniciais do Ensino Fundamental I, II, III e IV; Coordenadora Pedagógica na Secretaria Municipal da Educação, no Dept ${ }^{\circ}$ de Educação Infantil.

${ }^{2}$ Conforme Lei ${ }^{\circ} 11.114$, de 16 de maio de 2005. Altera os artigos 6 $6^{\circ}, 30,32$ e 87 da LDB/96, com o objetivo de tornar obrigatório o início do Ensino fundamental aos 6 anos de idade; e Resolução no 258 de 11/11/2005, a partir de 2006 as crianças que completar a idade de 6 (seis) anos até o mês de abril, devem ser matriculadas no $1^{\circ}$ ano do Ensino fundamental. Dessa forma, as Instituições de Educação Infantil compreende a faixa etária de zero a quatro anos e oito meses, porém, continuaremos nomeando tal qual os documentos citados menores de seis anos.
} 
is directly linked to the practice of education in a broader understanding. However, historically this course has not been aimed specifically at the education of children below 6 years of age. ${ }^{3}$ We understand that it is necessary to initiate and stress the importance of the formation of a specific educational policy for all public, free and good quality universities, which will help to achieve a formal level of education for those working within Early Years Education. This goes directly against neo-liberal political thinking, which is fashionable in contemporary society. The scientific production of Early Years Education will certainly contribute to a Graduate Course in this field which will be pertinent to future educators.

Key Words: Teacher Education and Formation, Early Years Education, Teaching Practice, Trainingship.

\section{Introdução}

Falar nas contribuições do curso de Pedagogia e, especificamente do estágio na formação de professores para Educação Infantil (EI), de uma certa forma, pode-se dizer que é uma novidade, visto que, as bases didáticas dessa etapa de educação no Brasil, se deram calcadas na herança de uma psicologia do desenvolvimento, pautada numa padronização de práticas homogeneizadoras, com as mesmas intenções das escolares. Para esse entendimento, é preciso destacar que as instituições de EI diferenciam-se essencialmente da escola enquanto às funções que desempenham. Partindo da sua própria organização: enquanto a escola tem o espaço privilegiado para o domínio dos conhecimentos básicos, as instituições de EI se colocam como espaço de complementaridade da educação da família.

Estabelecidas essas diferenciações, é preciso entender que o conhecimento didático - resultante de um conhecimento escolar e do processo de ensino - não é adequado para analisar os espaços das instituições de EI. Isso não significa dizer que o conhecimento e a aprendizagem não pertença ao universo da EI. Entretanto, a dimensão de conhecimentos para as crianças menores de seis anos se colocam numa relação extremamente vinculada ao de ser criança, com seus processos de constituição como seres humanos em diferentes

\footnotetext{
${ }^{3}$ According to Law n. 11.114 , of $16 / 05 / 2005$. It changes the $6^{\circ}$ article, 30,32 and 87 of the LDB/96, which makes it obligatory to start Primary Schooling at the age of 6; and Resolution $\mathrm{n}^{\circ} 258$ of 11/11/2005, which states that from 2006 on, every child aged 6 by April, must be enrolled in the first year of Primary School. Thus, Institutions of Early Years Education take those children from 0 to 4 years and 8 months old. However, we will call them as quoted in documents - those below the age of six years.
} 
contextos sociais, sua cultura, suas capacidades intelectuais, criativas, estéticas, expressivas e emocionais. Acreditamos que é esse conjunto de relações que poderiam ser identificados como objeto de estudo para uma Pedagogia de infância.

\section{Contribuições do Curso de Pedagogia na Formação dos Professores de Educação Infantil}

É preciso fazer um esforço constante para refletirmos sobre nossa prática docente, especialmente a que exercemos num curso de formação de professores para atuarem na EI. Neste texto, procuraremos trazer certos elementos que sirvam como ponto de partida para pensarmos sobre as contribuições das diferentes disciplinas que compõem o currículo do Curso de Pedagogia e, em específico, a formação de professores para atuarem na EI, que afinal, é a preocupação de todos nós comprometidos com essa etapa de educação.

Tomando curiosamente este tema, pensamos, de início, que valeria a pena dividi-lo em subtemas. Assim sendo, começaremos pelos aspectos, que consideramos mais abrangentes, deixando para posterior análise os mais restritos. Observando o proposto, identificamos em sua parte central "Contribuições do Curso de Pedagogia" - destina-se a atingir um fim - "a formação dos professores de EI". A primeira parte do tema restringe-se pela segunda e, na segunda, a expressão "formação" restringe-se a extensão "professores". Nesse sentido, entendemos que, de imediato, o que nos interessa é o professor na formação do qual o estágio pretende ter um papel significativo e a seguir, abordaremos as outras partes do tema. Este será nosso proceder metodológico, no que se segue.

Tentar definir a postura do professor é contextualizá-lo na sua prática, evidentemente, em sua prática desejável, visto que existe uma prática que se exercita e que, certamente não é a desejável, e principalmente daqueles que atuam em - creches instituições que trabalham com crianças menores de cinco anos.

Primeiramente e de um modo genérico, diria que o professor, e que a partir desse momento chamaremos de educador, é todo ser humano envolvido em sua prática histórica transformadora. Em nossas múltiplas relações, estamos dialeticamente situados num contexto educativo. Todos somos educadores e educando, conforme afirma Brandão 
(2005) "Ninguém escapa da educação. Em casa, na rua, na igreja ou na escola, de um modo ou de muitos todos nós envolvemos pedaços de vida com ela para aprender, para ensinar, para aprender-e-ensinar. Para saber, para fazer, para ser ou conviver, todos os dias misturamos a vida a educação" (p.7). Nesse sentido, ensinamos e somos ensinados, numa interação contínua, em todos os instantes de nossas vidas. Aqui não é preciso nenhuma preparação de aprendizagem específica para ser educador. Espontaneamente, aprendemos no nosso meio, com outros autores, com as próprias experiências, com nossas meditações pessoais. Adquirimos, no nosso processo dialético transformador, um amontoado de conhecimentos e sabedorias que pode, deve ser e é intecambiado em nossas relações sociais, com uma ou com várias educações.

Em segundo lugar, educador é o profissional que se dedica a atividade de ensinar intencionalmente. Segundo Luckese (1995) é aquele que cria condições de desenvolvimento de condutas desejáveis, seja do ponto de vista do indivíduo, seja do ponto de vista do grupo humano. Somos nós, quando passamos por um processo formal de aquisição de conhecimentos e habilidades, garantidos por uma instituição de nível superior ou não, atuar no magistério ou em outras atividades. Vencemos no decorrer de alguns anos, currículos e programas, tendo em vista nossa habilitação para atuar na EI ou séries iniciais do Ensino Fundamental.

Em ambos os casos, concebem o educador, antes de tudo, como um ser humano e, como tal, podendo ser sujeito ou objeto da história. Como objeto, sofre ação do tempo e dos movimentos sociais, sem assumir seu papel de interferidor nesse processo, nesse sentido, não desempenha o papel de educador em sua autenticidade. Como sujeito da história, podemos dizer que o educador autêntico é um ser, junto com outros, conscientemente engajado no "fazer" a história.

Entendemos que a educação por si só, não cria um modelo social, mas que ela atua dentro de um modelo social existente. Entretanto, acreditamos que o educador tem um papel fundamental no desenvolvimento e execução de um projeto histórico que esteja voltado para o homem, não será ele o executor das diretrizes e reformas educacionais, mas crítico e autor de um projeto histórico de desenvolvimento do povo, do qual é parte intrínseca. É como outros profissionais, construtor da história, na medida em que age conscientemente. O educador, aqui, é visto como um sujeito, que, conjuntamente com 
outros sujeitos, constrói seu agir, seu projeto histórico de desenvolvimento do povo, que se traduz e se executa em um projeto pedagógico. Assim sendo, ele não poderá exercer as suas atividades isentos de opções teóricas, ou então só porque gosta de crianças ou tem afeto por elas. Nesse sentido, a formação do educador apresenta hoje um grande desafio, principalmente em se tratando da formação para atuar em EI.

A LDB/96, em seu artigo 62 determina a formação mínima para os profissionais de EI seja no nível médio, na modalidade normal, embora a mais desejável seja a formação em nível superior, em cursos de licenciaturas, de graduação plena, em universidades e institutos superiores ou formados por treinamento em serviço.

Para responder esta meta ousada - visto que há um grande percentual de profissionais de EI não habilitados - pesquisadores e estudiosos com a causa da EI no Brasil, têm buscado soluções em cursos específicos para profissionais que atuam nessa área, discutindo a formação de maneira mais ampla, revendo os currículos atualmente em vigor, como o caso das "novas grades" curriculares dos cursos de formação de professores, e aqui se destaca a do curso Pedagogia da UFG/CAJ, que foi reestruturada, visto que até 2004 essa grade não previa o trabalho específico para a EI, tendo sido, a partir daí contemplada com essa disciplina.

Sabemos que não basta implementação de novas grades curriculares, acreditamos também que se faz necessário incorporar um novo perfil para esse educador desta etapa de educação. Nesse sentido, retornaremos às questões iniciais - a outra parte do tema de exposição - as contribuições do curso de Pedagogia -. Acreditamos, que as disciplinas do curso de Pedagogia precisa pensar para além da formação acadêmica, é preciso considerar questões relativas a ética, à cidadania; a concepções renovadas de crianças, de desenvolvimento infantil, de tempo, de espaço e de preparo para a atuação com os demais sujeitos envolvidos - desde as crianças atendidas e famílias envolvidas, até os organismos internacionais financiadores e formuladores de políticas de atendimento à criança pequena. Como preparar, educar, que concepções de formação seria preciso trabalhar na disciplina de Estágios em EI com os futuros profissionais para exercerem o cumprimento do duplo objetivo de cuidar e educar?

Um curso de "formação de educadores" comprometido com esses objetivos deve-se organizar e indicar caminhos que poderão ser percorridos, de propostas de trabalho 
que respeite a criança como indivíduos dotados de especificidades e singularidades, e inseridos em uma família, em uma sociedade, em uma cultura, conforme documentos publicado pelo MEC, em 1995, os quais indicam determinados critérios de qualidade para uma instituição que respeite a criança. Em primeiro lugar é preciso que a criança seja compreendida como sujeito em sua positividade. Mais do que simples proposições retóricas, o respeito à criança ganha concreticidade, na medida em que, nas práticas efetivadas, no interior das instituições de EI estejam previstas: brincadeiras, atenção individual; ambiente aconchegante, seguro e estimulante; o contato com a natureza; higiene e saúde; alimentação sadia; desenvolvimento da curiosidade, imaginação e capacidade de expressão de sentimentos; especial atenção no período de adaptação; desenvolvimento da identidade natural, racial e religiosa.

Esse espaço requer um profissional habilitado e com competências para articular educação-cuidado na sua prática cotidiana, no seu fazer educativo com crianças menores de cinco anos. Na defesa de uma formação de educadores para a EI, a partir de uma pedagogia da infância, que considere as especificidades e necessidades das crianças, como já abordamos anteriormente, é um grande desafio e um elemento essencial para a melhoria a qualidade do atendimento da criança pequena.

Precisamos compreender as diferentes funções da escola - anos iniciais do Ensino Fundamental - e da EI - creches, pré-escolas ou ambientes coletivos -, visto que elas têm diferentes perspectivas pedagógicas. A escola tem o espaço para o domínio dos conhecimentos básicos, como sujeito o aluno, como objeto o ensino em diversas áreas, desenvolvido por meio da aula, filas, divisão por idade, lápis e papel, mesa e cadeira, turma, instalação, disciplina, indisciplina, avaliação, eficiência, deficiência de aprendizagem, ensino, currículo... Diferentemente, a EI, tem como objeto as relações educativas travadas em um espaço de convívio coletivo, tem como sujeito a criança de zero a seis anos de idade. É preciso também preocupar, como afirma Faria (2005), com as especificidades dos espaços físicos para cada momento da vida das crianças: os móveis, brinquedos, objetos próprios para quem ainda não anda, literatura infantil sem textos, teatro, dança... É preciso também considerar questões relativas à ética, à cidadania e ao preparo para a atuação com demais agentes envolvidos tais como: criança, família e 
organismos financiadores e formuladores de políticas de atendimento às crianças menores de cinco anos.

A partir dessas diferenças, a concepção de conhecimento e aprendizagem é parte integrante da EI. Os conhecimentos adquiridos na educação das crianças pequenas associam-se aos processos de outras constituições, tais como: o brincar, a linguagem, o movimento, a fantasia, o imaginário... Essas habilidades são exigidas do profissional da EI, porém elas não são natas no indivíduo, portanto, devem ser adquiridas.

A questão histórica da criação das creches em nosso país e que está presente em vários discursos é que para cuidar de crianças pequenas tem de ser do sexo feminino, ter amor pelas crianças, ter jeito, gostar... Nesse sentido, há um pequeno investimento na formação desses profissionais. Se o que define uma boa educadora de creche são as características que não se refere a aquisição de conhecimentos científicos, não vale a pena investir nelas.

Libâneo (1994) destaca que várias áreas contribuem com os conhecimentos teóricos-práticos do fenômeno educativo. Como por exemplo, a Filosofia da Educação, a Sociologia da Educação, a Psicologia da Educação, a Antropologia, a Arte e Educação, a História da Educação, as Metodologias, dentre outras. Elas proporcionam a base para o entendimento dos movimentos da produção do conhecimento, elementos relativos à diferença e a influência de contextos característicos na construção da diversidade, como afirmação positiva e contrária à edificação de padrões de normalidade do ser humano, e especialmente da criança. Tais áreas dão suporte para os estágios em EI, além de proporcionar aos futuros profissionais dessa etapa da educação uma compreensão global do processo educativo, de oferecer referências para uma intervenção pedagógica e, ao associar essas áreas, expandir sua perspectiva, proporcionando uma abordagem dos processos em desenvolvimento humano a partir das relações com a sociedade e com a cultura.

Nessa perspectiva, formar esse educador seria criar condições para que o sujeito se prepare filosófica, científica, técnica e politicamente para o tipo de ação que vai exercer. Pimenta (2004) afirma que o exercício de qualquer profissão é técnico, no sentido de que necessita de técnica para executar as ações próprias. Assim, o médico, o dentista necessita desenvolver habilidades específicas para operar os instrumentos próprios de seu fazer. O educador também. Entretanto, as habilidades não são suficientes para a resolução dos 
problemas com as quais se defrontam; nem tão pouco gostar ou não de trabalhar com crianças pequenas. O educador nunca estará definitivamente "pronto", formado, visto que sua formação e maturação se darão no dia-a-dia, na meditação teórica sobre a sua prática. Os conhecimentos servirão de base para ver e compreender, na totalidade, o seu objeto de ação.

Ainda, segundo a autora acima citada, pode-se afirmar que no caso dos cursos de formação de professores e especialmente os destinados a EI, na maioria das vezes, nem fundamenta teoricamente a atuação do futuro profissional nem toma a prática como referência para a fundamentação teórica, isto é, carece de teoria e prática. Dessa forma, com que instrumental esse profissional vai atuar, se na sua formação não foi não lhe foi permitido o exercício dessa reflexão?

A formação do educador em EI requer, assim, uma sólida formação teórico prática. A referência histórica para uma pedagogia da infância podem ser nossos antigos pensadores também, que, mesmo sem falar em idade, falavam da educação das crianças na esfera pública, como: Comenius, Rousseau, Pestalozzi, Froebel, Dewey, Montessori - e como crítica de determinados pesquisadores - o próprio Piaget, não teria construído o conceito de "egocentrismo" se tivesse vivido um pouco mais e visto as crianças convivendo em creches.

Compreendemos a formação do educador nesta perspectiva, e entendemos que o estágio em EI poderá ser o elo fundamental entre concepções filosóficas-políticas da educação, e não o apêndice de orientações técnicas, mas um modo crítico de desenvolver uma prática educativa, forjada com um projeto histórico que considere a criança como criança, ou como cidadão de pouca idade que são, e não como um adulto em miniatura. Um trabalho construído, como afirma Ostetto (2000) entre encontros de educador-estudantes do campus com educador-profissionais do campo, com os olhos na realidade e vai nela penetrando por meio de um movimento de articulação de vozes, desejos e ações daqueles que estão em processo de formação inicial e daqueles que já estão atuando e que, no movimento, experimentam uma verdadeira formação em serviço.

Nessa perspectiva, todas as disciplinas que fazem parte da grade curricular de formação de educadores devem se colocar como possibilidade de articular e fazer ecoar essas múltiplas vozes que denunciam a situação precária da EI e pedem por materializações 
de ações coerentes. É preciso apontar o que "está bom" e o que precisa ser melhorado, ser mudado; estabelecendo relações de diálogo, de troca, tendo como horizonte a efetivação do direito das crianças brasileiras a uma EI de qualidade.

Estamos num movimento, pode se dizer, de uma nova profissão, de uma nova concepção de instituição educativa e de uma nova formação de profissionais - o profissional da EI -, que prevê para sua análise um olhar diferente. É um compromisso voltado a um público que não fala, que não anda, que não escreve, que não lê, que não negocia conosco. Acreditamos que esse caminho é uma construção coletiva dos sujeitos envolvidos nessa prática educativa - formadores e formandos -. É um caminho de descobertas sobre a condição infantil, suas necessidades, seus desejos e suas características específicas do "ser criança pequena".

É refletindo sobre os desafios encontrados na prática que o educador reconstrói a teoria e apropria de seu fazer, tornando-se livre para agir conscientemente. Não é possível sair da teoria e entrar na prática. Ao praticar, o educador reconstrói a teoria, que por sua vez re-inventa a prática. É incorporar um novo perfil para o educador de EI, distinto do perfil do ensinar alunos.

Ser educador na instituição de EI não é ser espontaneísta, porque as instituições não trabalham com conteúdo escolares e o educador não ministra disciplinas. Ele é um educador de crianças. É verdade que determinados pessoas manifestam especial tendência e gosto por crianças maiores ou menores, uns gostam mais, outros gostam menos do magistério. O que conta nessas instituições não é a técnica ou o "dom”, é o efeito da política na lógica do adulto sobre a criança. É lutar por uma micropolítica que não adapte às crianças ao saber e aos valores da sociedade do consumo e da alienação. Voltamos a afirmar, para isso, se faz necessário o domínio das bases teórico-científicas e técnicas, e sua articulação concreta com as exigências educacionais de uma instituição de EI. Essas questões permitem maior segurança do profissional, de modo que o docente ganhe base para pensar sua prática e aprimorar sempre mais a qualidade de seu trabalho.

Estudos realizados por Eloísa Rocha (1999), revelam que há uma nova geração de pesquisas, trazendo contribuições de categorias de análises a educação das crianças pequenas: o tempo, o espaço, as relações, o gênero, as classes sociais, os arranjos familiares, as transgressões, as culturas infantis, as diferenças, o outro, a linguagens, o 
brincar, o movimento, o gesto, a criança como criança, a alteridade, a observação, o cuidado, a não-avaliação.

Mesmo que as exigências de determinados alunos - do Curso de Pedagogia seja de um trabalho voltado às "receitas" no sentido de "técnicas" sobre o que fazer, gerando um distanciamento da vida e do trabalho concreto da instituição e o fortalecimento do mito das técnicas e das "receitas", é preciso que estes entendam que a criança é um ser humano competente, são "gentes" dotadas de múltiplas dimensões, portadores de história, produzidos e produtores de cultura, e sujeito de direitos. Não basta também apelar para os programas de formação (des)contínua, oferecidos pelas políticas educacionais, os quais estão em larga escala nas instituições de EI, tais como: proinfantil, proformação, dentre outros. Esses programas partem do pressuposto de que o conhecimento de técnicas e métodos é responsável pelos resultados do ensino. Está em movimento o ciclo da pedagogia compensatória, realimentando a ideologia do mito tecnológico.

É preciso garantir uma política, não só de estágio, mas de toda uma universidade pública, gratuita e da qualidade, que forme pedagogos para a EI, que vai de contramão com essas políticas neoliberais, tão em moda na sociedade contemporânea. A produção científica da EI certamente estará contribuindo para a Pedagogia da infância e conseqüentemente para uma política de estágio pertinente aos seus futuros educadores.

Como afirma Ostetto (2004) é preciso andar pelos lugares que realizam as práticas educativas, para conhecer os espaços concretos das relações entre adultos e crianças de zero a cinco anos. Esse conhecimento proporciona ao educador-estudante o conhecimento das instituições de EI, para buscar diálogo, para construir a competência profissional almejada e defendida como de qualidade. Dessa forma, acreditamos que, todas as disciplinas têm muito a contribuir neste campo, recriando o espaço do estágio como lugar de troca e interlocução. É nessa aproximação do lócus de formação com o lócus creches e pré-escolas públicas, num momento de abertura, de construção de relações tecidas no respeito às especificidades de cada instituição, que se constitui como contribuições do estágio na formação dos professores de educação infantil.

\section{REFERÊNCIAS:}


ANDRÉ, Marly. O papel da Pesquisa na formação e na prática dos professores. São Paulo: Papirus, 2001.

BRANDÃO, Carlos Rodrigues. O que é educação. São Paulo: Editora Brasiliense. 2005.

FARIA, Ana Lúcia Goulart. Políticas de regulação, pesquisa e pedagogia na educação infantil, primeira etapa da educação básica. Educação e Sociedade, v. 26 n 92. Campinas, 2005.

LIBÂNEO, José Carlos. Didática. São Paulo: Cortez, 1994.

LUCKESI, Cipriano. A avaliação da Aprendizagem Escolar. São Paulo: Cortez, 1995.

LIMA, Laís Leni O. Lima. Políticas Públicas Educacionais para a Educação Infantil de Jataí: da proposição à materialização. 2005. Dissertação (Mestrado em Educação) Faculdade de Educação, Universidade Federal de Goiás, Goiânia, 2005.

OSTETTO, Luciana Esmeralda (org.). Encontros e encantamentos na Educação Infantil. São Paulo: Papirus, 2000.

PIMENTA. Selma Garrido e LIMA, Maria S. L. Estágio e Docência. São Paulo: Cortez, 2004.

ROCHA. Eloísa Acires Candal. A Pedagogia e a Educação Infantil. In: ANAIS, $28^{a}$ Reunião Anual da ANPED, Caxambu - MG, out. 2005. p. 5-14.

\subsection{Documentos consultados}

BRASIL. Lei $\mathrm{n}^{\circ}$ 9.394/96, de 20 dezembro, 1996. Estabelece as diretrizes e bases da educação nacional. Diário Oficial da União. Brasília: 20 dezembro, 1996.

. Constituição da República Federativa do Brasil: Texto Constitucional promulgado em 5 de outubro de 1988, com as alterações adotadas pelas Emendas Constitucionais números 1/92 a 44/2004 e pelas Emendas Constitucionais de revisão números 1 a 6/94. Brasília - Senado Federal, Subsecretaria de Edições Técnicas, 2004.

. Lei $n^{\text {o }} 8.069$, de 13 de jul. de 1990. Dispõe sobre o Estatuto da criança e do adolescente, e dá outras providências. Estatuto da Criança e do Adolescente. Brasília: Imprensa Nacional, 1997.

.Resolução CEPEC n ${ }^{0}$ 731. Define a política da UFG para a formação de professores da Educação Básica. Goiânia, 2005. 
_. Lei $\mathrm{n}^{\mathrm{o}} 11.114$ de 16/05/2005. Altera os artigos $6^{\circ}$, 30, 32 e 87 da LDB/96, com o objetivo de tornar obrigatório o início do Ensino fundamental aos 6 anos de idade. Brasília: 16 de maio de 2005.

_. Resolução CEB n ${ }^{\circ} .258$ de 11/11/2005. Institui que as crianças com idade de 6 (seis) anos devem ser matriculadas no $1^{\circ}$ ano do Ensino fundamental. Diário Oficial da União. Brasília: 11 de Novembro de 2005. 